\title{
Peripheral Angiography
}

National Cancer Institute

\section{Source}

National Cancer Institute. Peripheral Angiography. NCI Thesaurus. Code C117879.

A procedure in which the catheter is passed into a peripheral vessel (usually in the groin)

for the purpose of angiography of the abdomen, hands, arms, feet and legs. 